\title{
Elastic thickness estimates at northeast passive margin of North America and its implications
}

\author{
R T Ratheesh Kumar ${ }^{1}$, Tanmay K Maji², Suresh Ch Kandpal ${ }^{2}$, \\ D SENGUPTA ${ }^{2}$ and RAJESh R NAIR ${ }^{1, *}$ \\ ${ }^{1}$ Department of Ocean Engineering, Indian Institute of Technology Madras, Chennai 600 036, India. \\ ${ }^{2}$ Department of Geology and Geophysics, Indian Institute of Technology, Kharagpur 721 302, India. \\ *e-mail: rajeshnair.iitkgp@gmail.com
}

\begin{abstract}
Global estimates of the elastic thickness (Te) of the structure of passive continental margins show wide and varying results owing to the use of different methodologies. Earlier estimates of the elastic thickness of the North Atlantic passive continental margins that used flexural modelling yielded a Te value of $\sim 20-100 \mathrm{~km}$. Here, we compare these estimates with the Te value obtained using orthonormalized Hermite multitaper recovered isostatic coherence functions. We discuss how Te is correlated with heat flow distribution and depth of necking. The E-W segment in the southern study region comprising Nova Scotia and the Southern Grand Banks show low Te values, while the zones comprising the NE-SW zones, viz., Western Greenland, Labrador, Orphan Basin and the Northern Grand Bank show comparatively high Te values. As expected, Te broadly reflects the depth of the $200-400^{\circ} \mathrm{C}$ isotherm below the weak surface sediment layer at the time of loading, and at the margins most of the loading occurred during rifting. We infer that these low Te measurements indicate Te frozen into the lithosphere. This could be due to the passive nature of the margin when the loads were emplaced during the continental break-up process at high temperature gradients.
\end{abstract}

\section{Introduction}

Various techniques have been used to characterize isostatic elastic thickness at the continental margins in different parts of the world (table 1). The simplest spectral method involves taking the ratio between the cross spectra and the power spectra of the gravity and topography data and comparing to flexural loading models. These techniques yield major variations in Te value and its relationship with parameters such as heat flow, depth of necking, etc. (Cochran 1979; Madsen et al 1984; Keen and Dehler 1997; Tiwari et al 2003; Daly et al 2004). The discrepancies still exist in these published estimates of Te. Therefore, there is a need to reassess the relationship of $\mathrm{Te}$ at continental margins based on our current estimates using the orthonormalized Hermite multitaper method.

Recent large-scale seismic surveys in the North Atlantic margin offer better constraints in the study of continental drifting and extension processes (Hopper et al 2004; Lau et al 2006). They deduced a first-order asymmetry in the final rift development of the conjugate Galicia Bank margin. These results further suggested the onset of ultraslow seafloor spreading of the Flemish Cap in the Newfoundland rifted margin.

The cross spectrum and power spectrum of gravity and topography data are estimated for both admittance and coherence functions. The wavelength dependence of the coherence and admittance varies with the window size of the analysed data

Keywords. Elastic thickness; gravity; coherence; North Atlantic passive continental margins. 
Table 1. Comparison of elastic thickness estimates at passive margins.

\begin{tabular}{|c|c|c|c|}
\hline Region & Investigators & Method & $\mathrm{Te}(\mathrm{km})$ \\
\hline $\begin{array}{l}\text { WCMI and eastern } \\
\text { ECMM }\end{array}$ & $\begin{array}{l}\text { Chand and Subrahmanyam } \\
\text { (2003) }\end{array}$ & $\begin{array}{l}\text { Free air admittance } \\
\text { analysis }\end{array}$ & $\begin{array}{l}\text { 8-15 (for WCMI) } \\
10-13(\text { for ECMM) }\end{array}$ \\
\hline India-EACM & Chand et al (2001) & $\begin{array}{l}\text { Free air admittance } \\
\text { analysis }\end{array}$ & $\begin{array}{l}\text { 10-25 (North ECMI \& } \\
\text { East EACM) } \\
<5 \text { (South ECMI \& } \\
\text { West EACM) }\end{array}$ \\
\hline $\begin{array}{l}\text { Continental margin off the } \\
\text { shore of West Africa }\end{array}$ & Watts and Stewart (1998) & Backstripping method & $0-10$ \\
\hline NACM & $\begin{array}{l}\text { Keen and Dehler (1997) } \\
\text { Ratheesh et al (2010) } \\
\quad \text { (Current study) }\end{array}$ & $\begin{array}{l}\text { Flexural modelling } \\
\text { Bouguer coherence-based } \\
\text { Hermite MTM }\end{array}$ & $\begin{array}{l}20-60 \\
2-8\end{array}$ \\
\hline
\end{tabular}

(Audet and Mareschal 2004). To test the effect of window size on the estimated coherence function, we perform our analysis with varying window sizes of $550 \times 550 \mathrm{~km}^{2}$ and $770 \times 770 \mathrm{~km}^{2}$. We investigate the isostatic elastic thickness and transitional wavelength for the North Atlantic passive continental margins in six zones using improved orthonormalized Hermite multi-tapersderived Bouguer coherence.

\section{Study region: Geological setting}

We define the regional geological setting based on three different classifications:

(i) Pre-rift phase,

(ii) Rifting phase, and

(iii) Post-rift phase

Rocks in the pre-rift phase are distinctly demarcated with the Permian basement overlain by a sedimentary cover of Late Triassic to Middle Jurassic age. Jansa and Wade (1975) and Barss et al (1979) recovered the oldest unmetamorphosed sedimentary rocks of the Devonian and Carboniferous ages. Late Triassic red bed and Evaporite sequences follow the shallow marine sequence of the early and middle Jurassic shales, carbonates and sandstones (Jansa and Wade 1975; Pegrum and Mounteney 1978).

On the basis of the structural style developed during the rifting phase (Montadert et al 1979; Robert et al 1979b), the North Atlantic passive margins are divided into two zones, viz., dipping reflector margins and tilted blocks margins. The dipping reflector margins are characterized by thick wedges of oceanward dipping seismic reflections, while the tilted block margins are characterized by listeric faulting, rotation of fault block and absence of synrift volcanism. Fault spacing is typically $5^{-}$ $30 \mathrm{~km}$ and fault throws could be as large as $4 \mathrm{~km}$ (Montadert et al 1979).
The post-rift phase begins with the generation of oceanic crust and the release of tensional stresses which dominate the rift phase. The postrift phase is dominated by regional subsidence generally resulting from thermal contraction of a cooling lithosphere (Sleep 1971). In general, postrift sediment units can be differentiated as an upper seismically layered unit of Oligocene and younger strata, a weakly layered Eocene age and lower black shale sequence (Groupe Galice 1979; Montadert et al 1979).

Earlier data suggested several explanations and raise the possibility of an extended oceancontinent transition in the Newfoundland Basin (Keen and de Voogd 1988; Reid 1994; Srivastava et al 2000) demarcated oceanic or ultra slow spreading oceanic crust. Tucholke et al (1989) and Enachescu (1992) obtained thinned continental crust or exhumed mantle based on several observations (Boillot et al 1987; Dean et al 2000). Lau et al (2006) and Funck et al (2003) used coincident multichannel seismic and wide angle reflection/refraction data. They deduce that the margin structure is much wider on the Galicia Bank margin in contrast with the Flemish Cap margin in the North Atlantic (Lau et al 2006; Funck et al 2003). The Flemish Cap margin is considered to be conjugate to the Galicia margin. The $2 \mathrm{D}$ velocity model across Grand Banks, Newfoundland revealed a 34-37 km thick crust and consists of an upper crustal velocity of $5.8-6.25 \mathrm{~km} \mathrm{~s}^{-1}$, middle crustal velocity of $6.3-6.53 \mathrm{~km} \mathrm{~s}^{-1}$ and lower crustal velocity of $6.77-6.9 \mathrm{~km} \mathrm{~s}^{-1}$. The signatures of rifting are demarcated as $170 \mathrm{~km}$ extended continental crust adjacent to the Carson Basin (Lau et al 2006). Hopper et al (2004) used prestack depth-migrated seismic data and obtained several deep reflections provided an evolutionary model of the Newfoundland drifted margin.

The geological setting of the six zones investigated includes Nova Scotia (NS), Southern Grand Banks (SGB), Northern Grand Banks (NGB), 
Orphan Basin (ORP), Labrador (LAB) and West Greenland (WGRN). The formation of the continental margin of NS commenced during the Early Mesozoic separation of Africa from North America. Subsequently, sedimentation of NS shelf from Late Triassic-Early Jurassic was strongly influenced by the configuration of Palaeozoic basement. SGB represents wide cratonic segment extended vigorously during the Late Triassic-Aptian rift-phase episodes accompanied by syntectonic basin filling. The ORP lying on the north of the SGB overlies a broad region of thinned crust at the continental margin. Triassic-Jurassic extension followed by Iberia-North America rifting in Cretaceous time developed the NGB. Several other studies (Srivastava and Tapscott 1986) demonstrate that various episodes of rifting in Cretaceous resulted in the LAB margin. The WGRN shelf is thus considered as the conjugate of the LAB margin.

\section{Data and methodology}

The equivalent topography map and Bouguer gravity map are shown in figures 1 and 2 . We used the free-air gravity data derived from the global marine gravity field from the ERS- 1 and GEOSAT geodetic mission altimetry of Andersen and Knudsen (1998) and Andersen et al (2008). The free-air gravity anomaly data, $\Delta G_{\mathrm{f}}$, is converted to Bouguer gravity anomaly, $\Delta G_{\mathrm{b}}$, using the slab formula and a surface rock/water density contrast of $\Delta \rho=1670 \mathrm{~kg} \mathrm{~m}^{-3}$, applied to the bathymetry data:

$$
\Delta G_{\mathrm{b}}=\Delta_{\mathrm{f}}+2 \pi \Delta \rho G H,
$$

where $H$ is the bathymetry in metres. We used the formula in Parker (1972) and then estimated the complete Bouguer anomaly which was used for this evaluation. The bathymetry data comes from GEBCO (General Bathymetric Chart of Oceans) digital 1 minute bathymetry data (NOAA 2003), which is converted to equivalent topography. Since the other bathymetric models derived from satellite altimetry free-air anomalies are sensitive to local compensation, we used the GEBCO digital data for our coherence estimation. The equivalent topography is the height or depth that the crust will assume in the absence of ice or water and under isostatic conditions, this is given by:

$$
h(x)=\left(\frac{\rho_{\mathrm{c}}-\rho_{\mathrm{w}}}{\rho_{\mathrm{c}}}\right) \times d,
$$

where $h(x)$ is the equivalent topography, $d$ is the bathymetry (in metres), $\rho_{\mathrm{c}}$ and $\rho_{\mathrm{w}}$ are the mean crustal density and the water density, respectively.
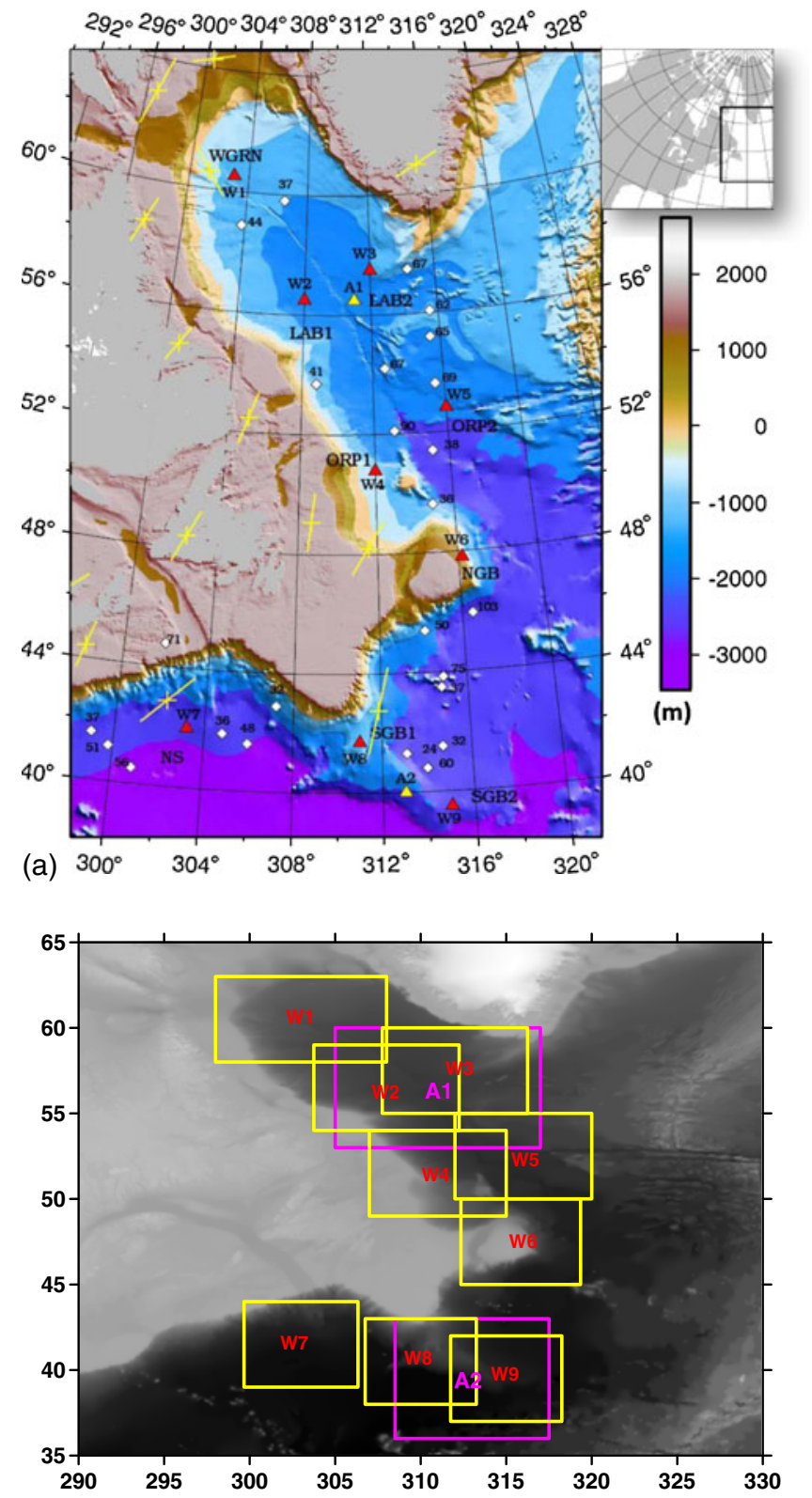

(b)

Figure 1. (a) Equivalent topography (metre) map showing the location of six transects (after Keen and Dehler 1997). The red triangles are the centres of nine windows, each of size $550 \times 550 \mathrm{~km}^{2}$, used for the estimation of elastic thickness. Two bigger window centres (yellow) of size $770 \times 770 \mathrm{~km}^{2}$ are used to demonstrate the effect of window size on elastic thickness estimation. Also shown are averaged maximum stress (yellow arrow) after Zoback (1992), heat flow data (white diamond) $\left(\mathrm{mWm}^{-2}\right)$ (Pollack et al 1993). Inset shows the location of study area with respect to North America. (b) The grey scale bathymetry map of the study region depicts the rectangular windows taken for Te estimation. The yellow boxes are of size $550 \times 550 \mathrm{~km}^{2}$ (W1-W9) and the two pink boxes are of size $770 \times 770 \mathrm{~km}^{2}$ (A1 and A2).

Even if the data does not pertain to any land, the scaling had to be done to derive equivalent topography that makes the bathymetry compatible with land-loading deconvolution equations. This is 


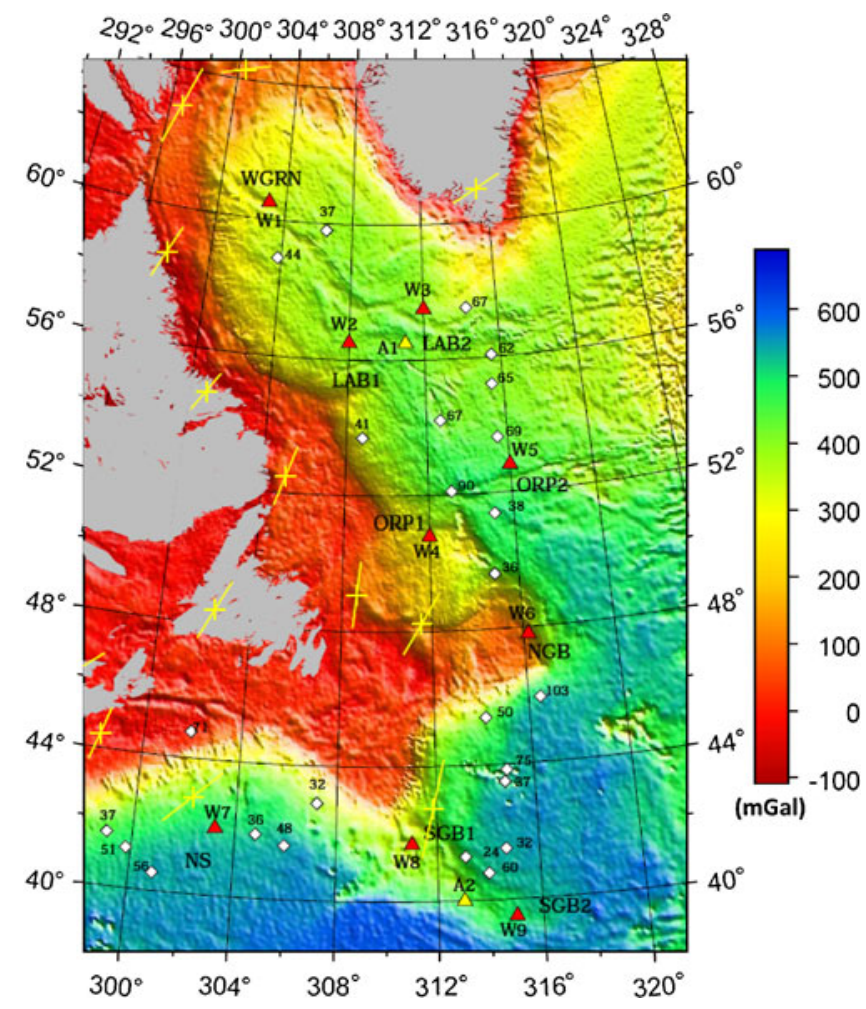

Figure 2. Bouguer gravity anomaly (mGal) data projected onto a Transverse Mercator grid superimposed with the features described in figure 1. Nova Scotia (NS), Southern Grand Banks (SGB); Northern Grand Banks (NGB); Orphan Basin (ORP); Labrador (LAB); West Greenland (WGRN).

because the inversion uses only the land-loading equations and not those for a water load. In addition, synthetic modelling also showed that Te was better recovered in all settings (i.e., land only, ocean only and mixed land-sea) when using the scaling as shown in equation (1) and only in land loading equations (Kirby and Swain 2008). Our data covers most of the eastern continental margins, adjoining ocean basins of North America and a small part of Western Greenland. After applying a Transverse Mercator projection, we extracted nine sub-grids of $\sim 550 \times 550 \mathrm{~km}^{2}$ for the estimation of the elastic thickness. The centres of the windows are shown in figures 1 and 2 . The total spans of the windows are shown in table 2. Since figures 1 and 2 are in Transverse Mercator projections, we have chosen our windows so that the distance span along longitude and latitude corresponds to $550 \times 550 \mathrm{~km}^{2}$ (W1 to W9) and $770 \times 770 \mathrm{~km}^{2}$ (A1 and A2). These windows are depicted in figure 1(a).

Elastic model parameters are shown in table 3. Moho depths (table 2) are taken from the Crust 2.0 model (Bassin et al 2000). We restricted our analysis well within the oceans so as to avoid the intricacies involved in the generation of satellite measurements from continental regions.

The isostatic response function has been used earlier to explain several geodynamic phenomena in oceanic regions. Daly et al (2004) computed the Te of the Irish Atlantic margin using the multitaper coherence method between scaled bathymetry and Bouguer gravity (we used the same methodology) and obtained low Te values ( 6-18 km). Tiwari et al (2003) used KMS02 data (Andersen and Knudsen 1998) to estimate the Te over the Ninety-East ridge, and obtained values of zero in the central ridge. We used a revised and better version of KMS02 data (Andersen and Knudsen 1998; Andersen et al 2008) for this study. Tassara et al (2007) used satellite KMS02 data (Andersen and Knudsen 1998) for South America and suggested that several regions of the oceanic plates and South America continental margins have an elastic thickness of less than $10 \mathrm{~km}$.

Coherence is the square of the spectral correlation coefficient between two fields. For studies of elastic thickness, coherence between the equivalent topography and Bouguer gravity anomaly is compared to the coherence functions calculated from theoretical models with given flexural rigidities.

Table 2. Location of the different windows and the crustal thickness used for Te inversion.

\begin{tabular}{|c|c|c|c|c|c|}
\hline \multirow{2}{*}{$\begin{array}{l}\text { Window } \\
\text { no. }\end{array}$} & \multirow{2}{*}{$\begin{array}{l}\text { Span along } \\
\text { longitude }\end{array}$} & \multirow{2}{*}{$\begin{array}{l}\text { Span along } \\
\text { latitude }\end{array}$} & \multirow{2}{*}{$\begin{array}{c}\text { Crustal } \\
\text { thickness }(\mathrm{km})\end{array}$} & \multicolumn{2}{|c|}{ Surface distance per $1^{\circ}$ change } \\
\hline & & & & In longitude $(\mathrm{km})$ & In latitude $(\mathrm{km})$ \\
\hline W1 & $298-308$ & $58-63$ & 15 & 55 & 110 \\
\hline W2 & $303.75-312.25$ & $54-59$ & 16 & 64.705 & 110 \\
\hline W3 & $307.75-316.25$ & $55-60$ & 12 & 64.705 & 110 \\
\hline W4 & $307-315$ & $49-54$ & 20 & 68.75 & 110 \\
\hline W5 & $312-320$ & $50-55$ & 11 & 68.75 & 110 \\
\hline W6 & $312.35-319.35$ & $45-50$ & 13 & 78.571 & 110 \\
\hline W7 & $299.67-306.33$ & $39-44$ & 15 & 82.582 & 110 \\
\hline W8 & $306.75-313.25$ & $38-43$ & 11 & 84.615 & 110 \\
\hline W9 & $311.75-318.25$ & $37-42$ & 12 & 84.615 & 110 \\
\hline $\mathrm{A} 1$ & $305-317$ & $53-60$ & 11 & 64.166 & 110 \\
\hline $\mathrm{A} 2$ & $308.5-317.5$ & $36-43$ & 12 & 85.555 & 110 \\
\hline
\end{tabular}


Table 3. Elastic model parameters.

\begin{tabular}{ll}
\hline Parameters & \multicolumn{1}{c}{ Value } \\
\hline$\sigma$ (Poisson's ratio) & 0.25 \\
$E$ (Young's modulus) & $10^{11} \mathrm{~N} / \mathrm{m}^{2}$ \\
$\rho_{c}$ (mean crustal density) & $2850 \mathrm{~kg} / \mathrm{m}^{3}$ \\
$\rho_{m}$ (mean mantle density) & $3350 \mathrm{~kg} / \mathrm{m}^{3}$ \\
$\rho$ (sea water density) & $1030 \mathrm{~kg} / \mathrm{m}^{3}$ \\
Crustal thickness & Crust 2.0 \\
\hline
\end{tabular}

Short-wavelength loads attributed to topography or internal density contrast are incoherent with the Bouguer gravity anomalies as they are supported by the strength of the plate. In the case of long wavelength loads, the deflection of the plate produces a compensation, and this causes the gravity anomaly produced by the flexure to be consistent with the topography (Audet and Mareschal 2004; Rajesh and Mishra 2004). The transitional wavelength from high to low coherence depends on the rigidity of the plate and is used to determine the elastic thickness of the lithosphere. The appendix provides the details of coherence computation and Hermite polynomial mathematical equations. Two spectral methods are commonly used to estimate Te: one is the coherence between Bouguer gravity anomalies and topography, and the second is the measure of admittance between the free-air gravity anomaly and topography. There is a significant difference between the two methods in case of the continental regimes. Mckenzie (2010) has shown that for long wavelengths, ' $\lambda$ ' is greater than or equal to $500 \mathrm{~km}$, and that continental admittance is often controlled by dynamically supported gravity and topography. However, it is easier to determine $Z(K)$ accurately in oceanic than in continental regions because continental values of the coherence are strongly affected by sub-aerial erosion. In the application of the Te (thin elastic plate modelling) to the oceanic lithosphere, we assume that the deformations in the elastic lithosphere are smaller compared to the deformation in the elastic layer of the continental lithosphere.

As the age and thickness of the lithosphere increase in the oceans, so does the Te. However, Te is always less than the seismogenic thickness Ts. This is because Te follows the isotherm between $300^{\circ}$ and $600^{\circ} \mathrm{C}$, while the Ts closely follows the $600^{\circ} \mathrm{C}$ isotherm (Watts 2001). The assumption in the estimation of elastic thickness implies that we have only vertical loads and no horizontal stresses, and that the mantle is effectively fluid. The physical meaning of Te thus implies the apparent strength of the lithosphere that is expressed as the flexural rigidity ' $D$ ', which in turn, is commonly expressed through the effective elastic thickness $\left(T_{\mathrm{e}}\right)$ of the lithosphere. Our values are first-order estimates of the effective elastic thickness; our physical interpretations of course depend on the meaning of 'effective' and we discuss this uncertainty later in the text.

In the coherence method employed in this study, tapers are applied to both the rows and the columns of the gravity and topography data. The algorithm iterates to obtain a series of predicted coherence curves for different Te values and for the chosen value of the loading ratio ' $f$ '. The predicted curve is compared with the observed curve and the value of Te that minimizes the root mean square error (RMSE) is estimated.

Simons et al $(2000,2003)$ provide a complete description of the multitaper method (MTM) applied to flexural studies. Figure 3 shows calculated coherence values for $R=2,3,4$ and the predicted coherence for a set of Te values. In each dimension, the number of tapers used for each value of $R$ is equal to $R^{2}$. We notice that calculated coherence values for $R=2$ and $R=4$ lie on either side of that for $R=3$. The error bars in the coherence curves are smaller for $R=3$ compared to $R=2$ and $R=4$. It is evident from figure 3 that for different values of $R$, the value of best-fitting Te is different. Hence as a trade off, we chose to take $R=3$ and 9 tapers in each dimension (a total of 81 different Hermite tapers) for our coherence measurements. Simons et al (2003) have demonstrated with synthetic data that $R=3$ gives the best results. Our tests with synthetic data yield results identical to Simons et al (2003) which confirms the suitability of the choice of $R=3$. Increasing the value of $R$ decreases the resolution. Our test with the observed data on several windows confirms the results obtained by Simons et al (2003). In this study, we employed the Bouguer coherence method of Forsyth (1985), with the coherence estimated via the Hermite-window multitaper method used by Simons et al (2003). While Simons et al (2003) provide low-variance estimates of the coherence between gravity and topography as a fairly uniform average over a selection of wavenumber ranges, Forsyth (1985) attempts to find the effective elastic thickness by fitting a parameterized curve through it. This is possible due to the load deconvolution that is implicit in the Forsyth method as we use it. The deliberate spectral bias introduced by the multitaper analysis of the data similarly influences the predicted coherence, which has led to reasonably faithful recovery of the elastic thickness in synthetic tests. We do caution that the relative estimation of elastic thickness is more reliable than the absolute values, which may contain additional bias. McKenzie (2010) argued that the elastic thickness of the cratons was in fact comparable to the elastic thickness of the oceans, although the low coherence between gravity and topography makes it more 

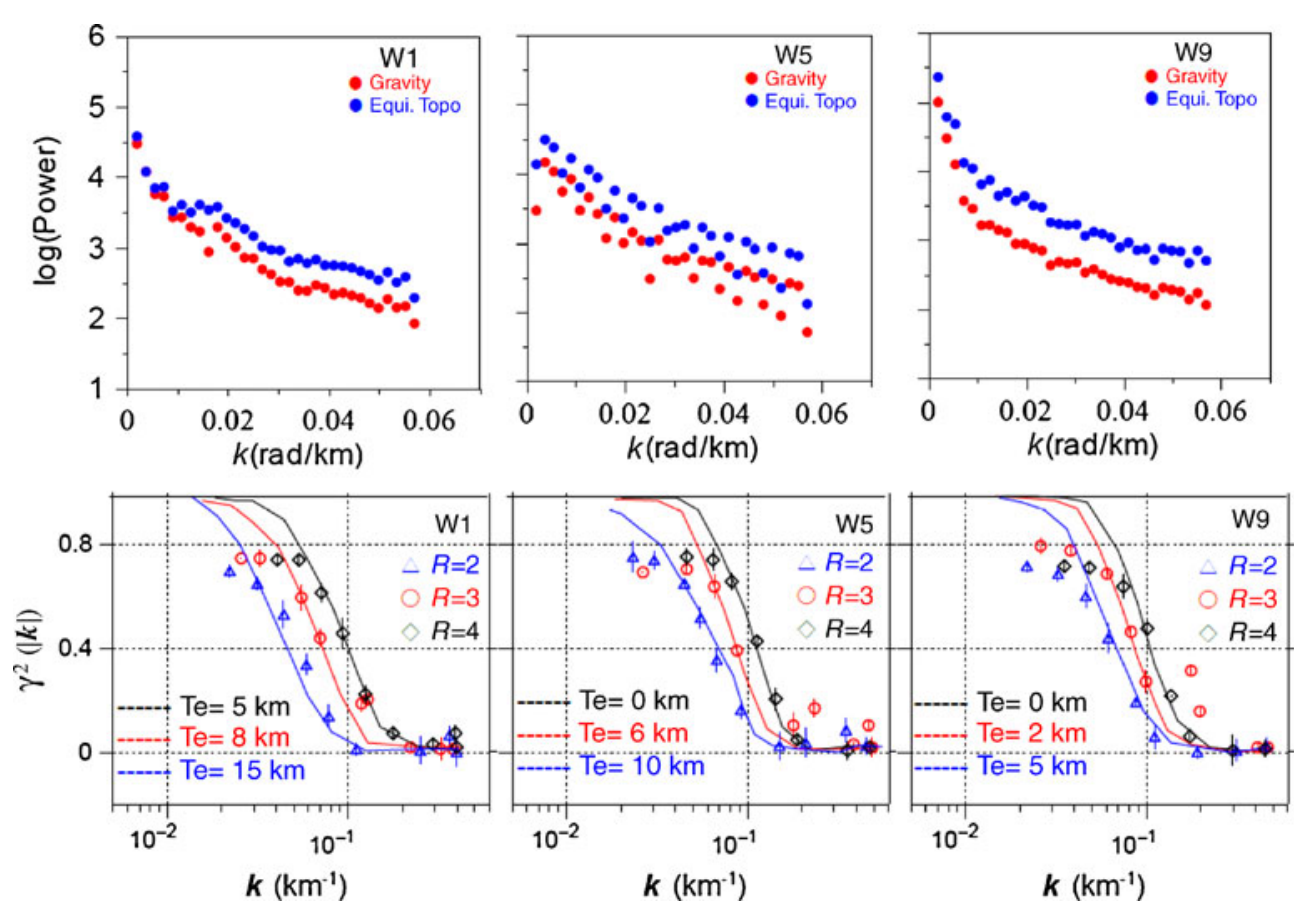

Figure 3. Coherence between Bouguer gravity and topography for the region is shown in figures 1 and 2 . From top to bottom: the radially averaged power spectrum of gravity and topography for these blocks, coherence square function for a set of values of $R$ (calculated) and Te (predicted). W1: WGRN; W5: ORP2; W9: SSGB2.

difficult to estimate with accuracy. While Mckenzie (2010) advocated using free-air anomaly rather than Bouguer gravity anomaly, and the admittance rather than the coherence between gravity and topography, we remain confident that the Bouguer coherence method would lead to results that are quantitatively interpretable on the level that is attempted in this paper. Since free-air coherence is high in the marine realm, estimates of Te from freeair admittance and Bouguer coherence would be similar. Therefore, it does not really matter which method is used. The situation is quite different in the cratons, where estimates of Te can differ by an order of magnitude because the coherence is reduced by subsurface loads without topographic expression (Mckenzie and Fairhead 1997; Mckenzie 2003, 2010).

\section{Results and discussion}

Figure 4 shows estimated values of the effective elastic thickness using the multispectrogram method. Estimation of effective elastic thickness is optimized using an L2 misfit norm. Forward models of coherence are computed using Forsyth's (1985) equations. The RMSE is computed at each point (figure 4) by taking into account the observed and predicted coherence values. The best fit is considered to be the lowest value of $\mathrm{Te}$ at which the RMSE drops to its minimum. Our measurements thus represent minimum estimates. The Te estimates are obtained wherever the RMSE between the observed and the predicted coherence curves drops to a minimum value. In this study, the inversion scheme for obtaining the elastic thickness employs the L2 norm. Our initial test using synthetic data with varying window sizes $550 \times 550 \mathrm{~km}^{2}$ and $770 \times 770 \mathrm{~km}^{2}$ confirms that errors in the estimation of Te can vary from $1-2 \mathrm{~km}$ only. We indeed tested estimation of $\mathrm{Te}$ values in several other overlapping windows. These tests confirm that the window numbers shown in this paper optimally represent significant variation in Te values pertaining to our study area.

The RMS plots are found to be sharp in similar studies by Daly et al (2004) in the Irish margin. The effective elastic thickness is estimated through an iterative process wherein the subsurface load plays an important role in the estimation of coherence. With the improved data quality (Andersen et al 2008), the coherence analysis can be very useful to estimate the loading mechanism and the elastic thickness. The coherence values for most of the windows are greater than 0.5 , indicating that coherence is a viable tool for estimating the Te structure. In using the coherence method, our main aim is to find the transitional wavelength over which the coherence value changes from high to low. It is not necessary for the coherence value to reach 1. Audet and Mareschal (2004) have also explained that the MTM resolves long wavelengths 

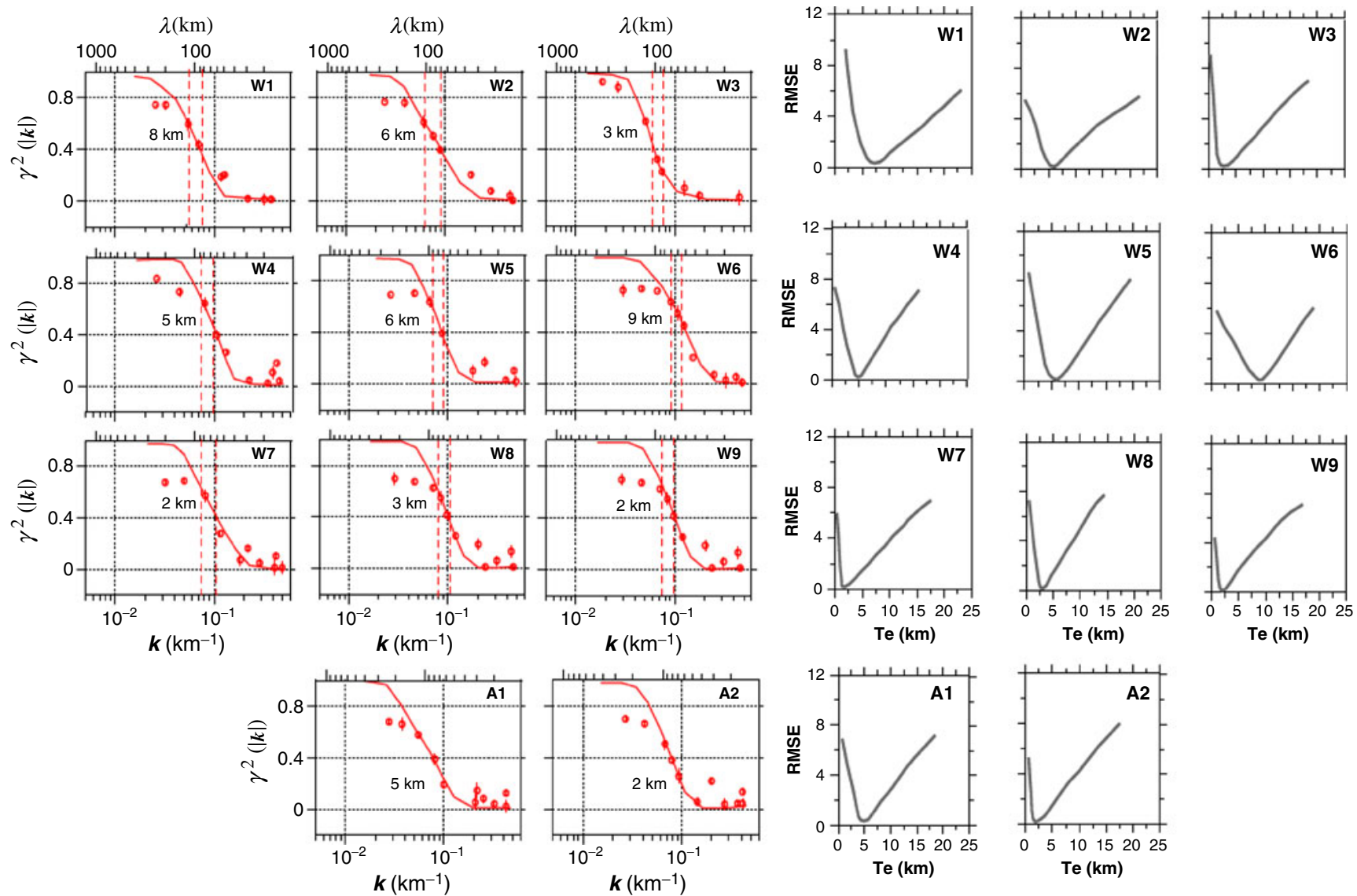

Figure 4. Left: Te inversions based on multitaper coherence analysis for data windows. Predicted coherence is indicated by solid lines and depicted by symbols. Right: Model misfit in the inversion of Te for windows. Plotted is a root mean square error (RMSE) calculation based on the misfit between observed and predicted Te values. W1 - WGRN, W2 - LAB1, W3 - LAB2, W4 - ORP1, W5 - ORP2, W6 - NGB, W7 - NS, W8 - SGB1, W9 - SGB2, and A1, A2 - bigger windows respectively (see figure 1 for locations).

poorly. However, this does not affect the estimated Te value substantially as demonstrated by several published results, for e.g., Simons et al (2003); Daly et al (2004); Rajesh and Mishra (2004). In Simons et al (2003), the coherence value is well below $1 \quad(<0.5$ in some cases) and the results obtained are reasonable. For every coherence estimate $\gamma^{2}(k)$, we determine the transitional coherence wavelength $\left(\lambda_{1 / 2}\right)$ at which the coherence drops to half of its maximum value. The band of transitional wavelength (which is equivalent to lithospheric thickness) is shown as vertical dotted lines in figure 4 . The transitional wavelength is a quality check for the Te estimates. In general, transitional wavelength is high for large Te values and vice versa. The transitional coherence wavelength varies from 70 to $100 \mathrm{~km}$. A similar value of transitional wavelength $(\sim 100 \mathrm{~km})$ was also obtained for the Indian plate in Gondwanaland which was a rifted segment that moved away from Antarctica (Kumar et al 2007). We used two bigger windows of size $770 \times 770 \mathrm{~km}^{2}$ for Te estimation (figure 4, windows A1, A2). However, our tests with varying window sizes of $550 \times 550 \mathrm{~km}^{2}$ and $770 \times 770 \mathrm{~km}^{2}$ did not affect the Te results to any appreciable extent. Using two different window sizes, we ensured that window size does not affect the Te values to any considerable extent. For example, Stephen and Singh (2003) used MTM spectral analysis for estimating Te in the south Indian shield. They used window sizes of $450 \times 450 \mathrm{~km}^{2}$, $620 \times 620 \mathrm{~km}^{2}$ and $750 \times 750 \mathrm{~km}^{2}$. These results show that window sizes of the above orders have the ability to capture the elastic behaviour of the lithosphere. In another study, Daly et al (2004) used window sizes of $500 \times 500 \mathrm{~km}^{2}$ to map variations in Te in the central part of the entire dataset, and could retrieve elastic behaviour of the margin. Our present measurements with window sizes of $550 \times 550 \mathrm{~km}^{2}$ and $770 \times 770 \mathrm{~km}^{2}$ is thus comparable to the range used successfully by Daly et al (2004) and Stephen and Singh (2003).

Table 1 shows the estimates of elastic thickness in similar passive continental margins across the globe. Using the free-air admittance method, Chand and Subrahmanyam (2003) obtained elastic 
thickness values of $8-15 \mathrm{~km}$ for the Western Continental Margin of India (WCMI) and 10-13 km for the Eastern Continental Margin of Madagascar (ECMM). In another study in the India-East Antarctica conjugate margins that also used free-air admittance analysis, Chand et al (2001) obtained Te values $\sim 10-25 \mathrm{~km}$ for northern part of the Eastern Continental Margin of India (ECMI) and the eastern part of the EACM and Te $<5 \mathrm{~km}$ for the southern part of the ECMI and the western part of the EACM. Using the backstripping method, Watts and Stewart (1998) obtained Te values of $\sim 0-10 \mathrm{~km}$ for the continental margin off the shore of West Africa. Thus, our estimated low Te values $(2-8 \mathrm{~km})$ are in close agreement with that of Watts and Stewart (1998). Keen and Dehler (1997) obtained higher Te values $\sim 20-60 \mathrm{~km}$ in the North Atlantic continental margin. This is in contrast to our results. However, Keen and Dehler (1997) mention that their Te values might represent some time-averaged load dependent behaviour instead of lithospheric strength.

The transitional wavelength estimated by $\lambda_{1 / 2}$ from isostatic coherence measurements show that NS and SGB with characteristic lithospheric thinning support our observations (figure 5 shows the relation between transitional wavelength and effective elastic thickness). ORP and NGB show a comparatively high Te with respect to NS and SGB and with almost similar values of transitional wavelength. These findings predict the intermediate thermally decaying phase in ORP and NGB. At the same time, WGRN and LAB show high Te as well as comparatively high transitional wavelength of $\sim 90-100 \mathrm{~km}$. The variations in heatflow over the various tectonic subdomains versus measured $\mathrm{Te}$ values (figure 6) will be discussed in the subsequent paragraphs.

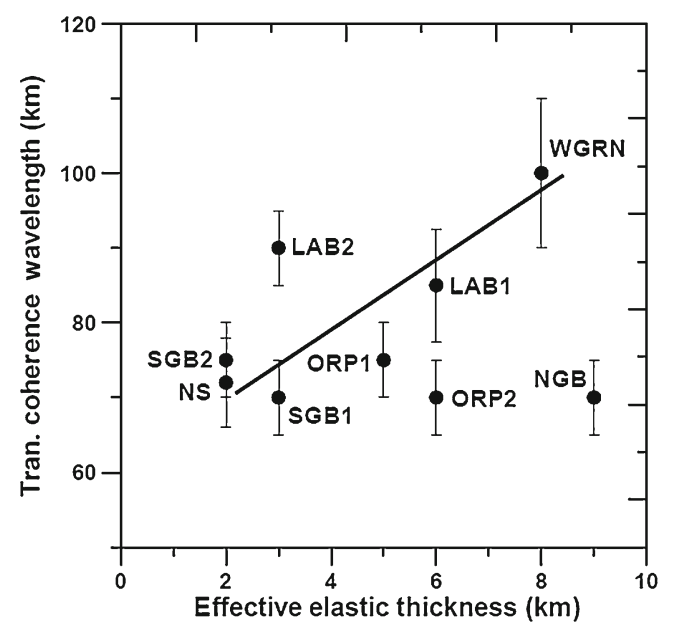

Figure 5. Transitional coherence wavelength by effective elastic thickness for windows (1-9). Vertical bars show the upper and lower limits of the lithospheric thickness.

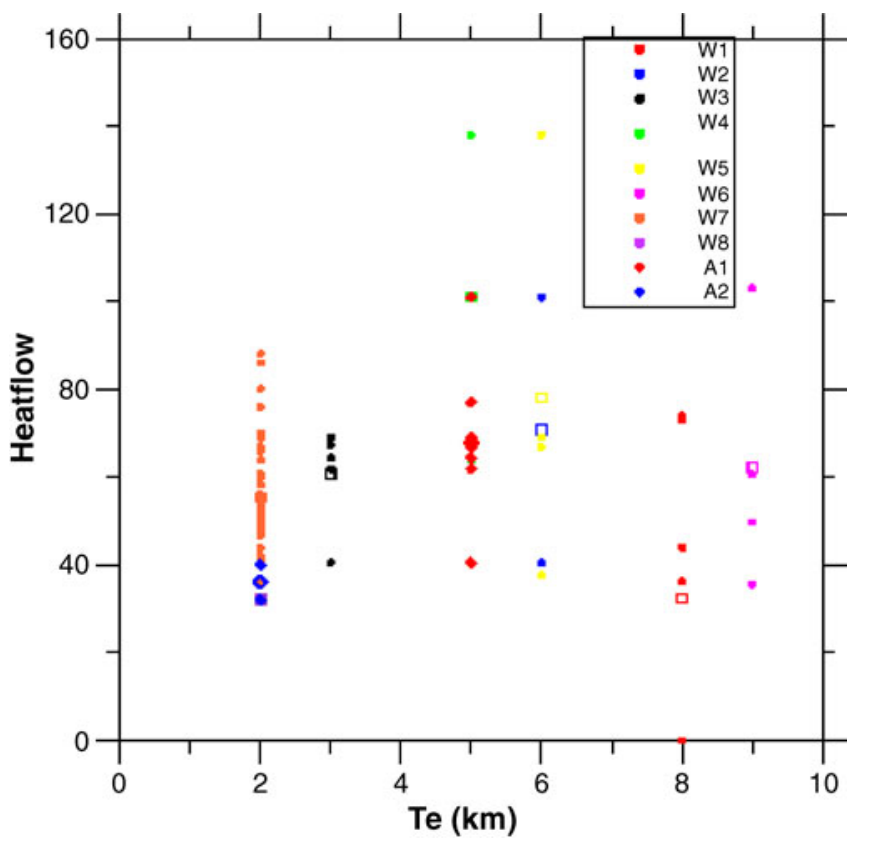

Figure 6. Heatflow values plotted against the elastic thickness values for all the windows except W8. No heatflow data was available for W8. Average heatflow values for each window are shown by the square symbols.

In the oceans, physically Te is controlled mostly by the rheology and temperature of the lithosphere (Watts 2001). One parameter that has been previously used to predict the flexural response of the lithospheric stretching is the depth of necking (DON) (Braun and Beaumont 1989; Weissel and Karner 1989a, 1989b). DON is defined as the level which remains horizontal, i.e., there is no vertical movement in the absence of gravity (Braun and Beaumont 1989). Keen and Dehler (1997) performed sensitivity studies in the North Atlantic Margins using synthetic modelling. They used quantitative estimation of DON values to relate to the state of flexure and the strength of the lithosphere. They demonstrated that, for a shallower DON value $(10 \mathrm{~km})$, both the airy and flexural models produce similar gravity and elastic thickness values, but for large DON $(20 \mathrm{~km})$ values, these two models of isostatic compensations differ significantly. Thus, they argued that depending on the DON value, basin and margins may sometimes show locally compensated character even though they have considerable mechanical strength (Keen and Dehler 1997). We compare our Te estimates in the same region with the DON estimates of Keen and Dehler (1997). Figure 7 reveals the relation between the Te and the DON in the different tectonic regimes of the North Atlantic passive margin. We obtained the lowest Te range $(2 \mathrm{~km})$ over the Nova Scotia region that is distinguished with highest DON $(22 \mathrm{~km})$. In the SGB 


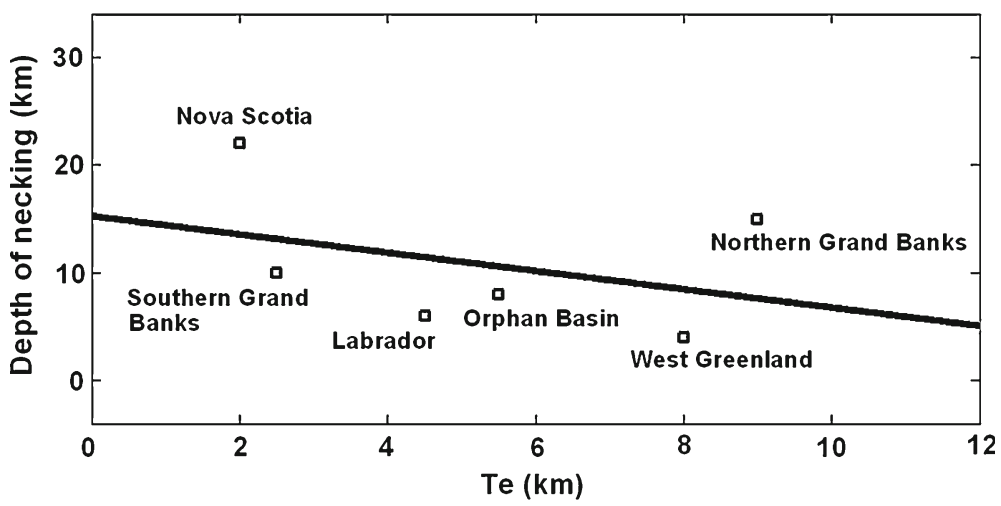

Figure 7. Te vs. DON plot for Nova Scotia, Southern Grand Banks, Northern Grand Banks, Orphan Basin, Labrador and West Greenland.

province lying adjacent to the NS, the Te range improves to $2.5 \mathrm{~km}$, but the DON drops to $10 \mathrm{~km}$. The LAB (Te $\sim 4.5 \mathrm{~km}$, DON $6 \mathrm{~km})$, WGRN (Te $\sim 8 \mathrm{~km}$; DON $\sim 4 \mathrm{~km}$ ) and ORP (Te $5.5 \mathrm{~km}$; DON $8 \mathrm{~km}$ ) in the NNE-SSW regimes fall under the low DON range. On the other hand, the NGB lying adjacent to the ORP has high strength (Te $9 \mathrm{~km}$ ), and exhibits an average high range of DON $(\sim 15 \mathrm{~km})$. Thus, most of these tectonic zones seem to exhibit an inverse relationship between Te and DON. This observation is consistent with the idea of Braun and Beaumont (1989), Weissel and Karner (1989a, 1989b) and Kooi et al (1992) that necked regions differ from the predicted airy model.

We consider the rock/water density contrast to have increased/decreased by 10\%, $20 \%$ and so on. We could not find any change in retrieved Te values for $10 \%$ contrast, with a small effect of $\pm 1 \mathrm{~km}$ in retrieved Te value for $20 \%$ variations in density contrast. Braitenberg et al (2006) were of the view that the reference depth and the density contrast should be allowed to vary within standard values of $20-30 \mathrm{~km}$ and $350-600 \mathrm{~kg} / \mathrm{m}^{3}$, respectively. The gravity field is inverted for several combinations of parameters and the RMS difference with the constraining values of Moho from seismic reflection data have been calculated. These estimates reveal a best agreement $(1.8 \mathrm{~km} \mathrm{rms})$ between gravityderived and seismically-measured Moho with Te variations of $1-3 \mathrm{~km}$ only. Hence, the Te variations based on the variations of these physical constraints are not significant in this study.

Heat flow observations (Pollack et al 1993) show variations in average heat flow values in the NNE-SSW and E-W segment with comparatively high values consistently for both the provinces. We examined whether heat flow may be a factor in controlling the elastic properties of the lithosphere. Heat flow values vary from $35-70 \mathrm{mWm}^{-2}$ in various provinces. Figure 6 is a plot showing the scatter of heat flow in the study region over various tectonic subdomains (W1-WGRN, W2-LAB1, W3-LAB2, W4-ORP1, W5-ORP2, W6-NGB, W7-NS, W8-SGB1, W9-SGB2, and $\mathrm{A} 1$ and A2, respectively). We did not obtain any clear distinction of estimated Te and heat flow distribution in the study region (figure 6). This scatter is even more inconsistent if the individual heat flow values of smaller domains are assessed. The low Te values with respect to heat flow distribution and depth of necking data remains rather unclear. We infer that these low Te measurements indicate Te frozen into the lithosphere. This could be due to the passive nature of the margin when the loads were emplaced during continental break-up process at high temperature gradients.

We infer that variable concentrations in heat generating elements cannot explain the lack of correlation between Te and heat flow in this case, simply because the crust is dramatically thinned in most of the study domain, and consequently the total heat that it produces should not be significant (unless exceptionally enriched in radioactive elements). Recent studies, including geological and geophysical investigation, point out that a few of the crustal faults are certainly weak in comparison with laboratory conclusions on frictional strength (Collettini et al 2009). The possible reasoning for fault weakness includes the presence of weak minerals, and the presence of high pressure fluid within the fault cores with normal stress reduction. These features might thus result in extreme weakening at high slip velocity (Byerlee 1978; Zoback et al 1987; Holdsworth 2004; Moore and Rymer 2007). These results therefore suggest that low effective elastic thickness values may reflect the presence of faults with low cohesion/friction that might have weakened the crust. The Te of the oceanic lithosphere increases with age and estimated values far from active plate boundaries approximately correspond to the depth of the $450^{\circ} \mathrm{C}$ isotherm 
(Watts 1978) due to the relatively simple composition and thermal evolution of the lithosphere. Te also varies with the curvature of flexure which may explain some of the scatter, and their conclusions support the numerical modelling of margins based on simple assumptions of isostasy (e.g., Crosby et al 2008). In these estimates, the Te values (2-9 km) thus broadly correlate with the 200$400^{\circ} \mathrm{C}$ isotherm at the time of loading. Our present observation of $\mathrm{Te}<10 \mathrm{~km}$ is reasonable since the thermal gradients during rifting may have risen by 2-3 times. In addition, this process generates a fluidized upper crust which makes it weak. However, over timescales lithospheric cooling might have resulted in an increase in rigidity at a few portions of the margins. The above descriptions are characteristics of passive margins and we infer that the obtained $\mathrm{Te}$ is thus frozen into the lithosphere.

\section{Conclusion}

Earlier observations in the North Atlantic margin were based on forward modelling of free-air gravity data and yielded Te values of $\sim 20-60 \mathrm{~km}$. We obtained low Te values $(2-8 \mathrm{~km})$ for the different windows at the North Atlantic passive continental margin, independent of the window sizes. The evidences we found of rifting (low $\mathrm{Te}$ ) are supported by estimated depth of necking with some minor exceptions. Our results agree well with those obtained using the backstripping method at the West African continental margin which yielded values of $\sim 0-10 \mathrm{~km}$. We have showed that the Hermite multitaper derived Bouguer coherence via optimal window sizes of $550 \times 550 \mathrm{~km}^{2}$ and $770 \times 770 \mathrm{~km}^{2}$ can capture spatial variation of the Te structure at such continental passive margins. We thus use a Bouguer coherence method with novel Hermite multi-tapering windows to estimate the Te of continental margins in the NW Atlantic. We find that the Te of the terrain was low $(0-8 \mathrm{~km})$ at the time of its formation, and that this range of values is insensitive to geological age. This result implies that oceanic rifting is a process that is essentially isostatic and has important implications for dynamic modelling of the breakup process.

\section{Acknowledgements}

Funding from INCOIS/Tsu/08-09 and DST ES-35 is gratefully acknowledged. We also sincerely thank the three anonymous reviewers for their insightful suggestions which helped in improving the manuscript.

\section{Appendix}

For two nonstationary random processes $\{X\}$ (gravity) and $\{Y\}$ (topography), defined on $r$ in the spatial domain and on $k$ in the Fourier domain, the square of the coherence function relating both fields, $\gamma_{X Y}^{2}$ is defined as the ratio of their crossspectral density, $S_{X Y}$, to the product of the individual power spectral densities, $S_{X X}$ and $S_{Y Y}$ (Bendat and Piersol 2000)

$$
\begin{aligned}
& \gamma_{X Y}^{2}(r, k)=\frac{\left|S_{X Y}(r, k)\right|^{2}}{S_{X X}(r, k) S_{Y Y}(r, k)} \\
& \quad=\frac{\left|E\left\{\tilde{X}(r, k) \tilde{Y}^{*}(r, k)\right\}\right|^{2}}{E\left\{\tilde{X}(r, k) \tilde{X}^{*}(r, k)\right\} E\left\{\tilde{Y}(r, k) \tilde{Y}^{*}(r, k)\right\}},
\end{aligned}
$$

where $E$ denotes an expectation operator, tildes refer to the Fourier-transformed signal, and the asterisk refers to the complex conjugate. The periodogram $\tilde{X} \tilde{X}^{*}$ is a direct spectral estimator of $X$, although not a particularly accurate one.

The MTM consists of calculating the spectra with multiple orthogonal windows used as data tapers and averaging over different (approximately) independent subsets of the data (Percival and Walden 1993). We have used orthonormal Hermite functions as data taper, which are the eigenfunctions of the operators concentrating in a discshaped time frequency domain $t^{2}+(2 \pi f)^{2} \leq R^{2}$. They are Hermite polynomials modulated by a Gaussian function.

$$
h_{j}(t)=\frac{H_{j}(t) e^{-t^{2} / 2}}{\pi^{1 / 4} \sqrt{2^{j} j !}} .
$$

Hermite polynomials can be calculated using the recurrence relation:

$$
H_{n+1}(t)=2 t H_{n}(t)-2 n H_{n-1}(t),
$$

starting from $H_{0}(t)=1$ and $H_{1}(t)=2 t$.

The number of tapers are independent of the choice of functions (Slepian or Hermite). One decides the number of tapers based on the best trade-off between the resolution and variance. The Hermite tapers are better than the Slepian tapers in the sense that the Hermite tapers have a circular concentration $(t, f)$ domain compared to the rectangular concentration domain of the Slepian tapers. Due to the circular domain, optimal resolution in time and frequency can be simultaneously achieved without compromising either of them (Simons et al 2003). Another important property of the Hermite tapers is that the eigenfunctions of the concentration operator is independent of 
the width of the domain which makes the Hermite taper computationally much faster than the traditionally-used Slepian tapers.

\section{References}

Andersen O B and Knudsen P 1998 Global marine gravity field from ERS-1 and GEOSAT geodetic mission altimetry; J. Geophys. Res. 103 8129-8137.

Andersen O B, Knudsen P, Berry P, Freeman J, Pavlis N and Kenyon S 2008 The DNSC07 Ocean wide altimetry derived gravity field; Presented EGU (2008), session G1, General Assembly, Vienna, Austria, April 14-18.

Audet P and Mareschal J C 2004 Variation in elastic thickness in the Canadian Shield; Earth Planet. Sci. Lett. 226 $17-31$.

Barss M S, Bujak J P and Williams G L 1979 Palynological zonation and correlation of sixty-seven wells, Eastern Canada; Geol. Surv. Canada, paper 78-24, 118.

Bassin C, Laske G and Masters G 2000 The current limits of resolution for surface wave tomography in North America; EOS Trans. AGU $81 \mathrm{~F} 897$.

Bendat J S and Piersol A G 2000 Random Data: Analysis and Measurement Procedures, 3rd edn. (New York: John Wiley).

Boillot G, Winterer E L, Meyer A W and Shipboard Scientific Party 1987 Proceedings of the Ocean Drilling Program, Initial Reports, 103 (ed.) Littleton R M, Ocean Drilling Program, College Station, Texas.

Braitenberg C, Wienecke S and Wang Y 2006 Basement structures from satellite-derived gravity field: South China Sea ridge; J. Geophys. Res. 111 B05407.

Braun J and Beaumont C 1989 A physical explanation of the relationship between flank uplifts and the breakup unconformity at rifted continental margins; Geology $\mathbf{1 7}$ 760-764.

Byerlee J D 1978 Friction of rocks; Pure Appl. Geophys. 116 615-629.

Chand S and Subrahmanyam C 2003 Rifting between India and Madagascar-mechanism and isostasy; Earth Planet. Sci. Lett. 210 317-332.

Chand S, Radhakrishna M and Subrahmanyam C 2001 India-East Antarctica conjugate margins: Gravity and isostasy; Earth Planet. Sci. Lett. 185 225-237.

Cochran J R 1979 An analysis of isostasy in the world's oceans 2. Mid-ocean ridge crests; J. Geophys. Res. 84 4713-4729.

Cristiano Collettini, Andre Niemeijer, Cecilia Viti and Chris Marone 2009 Fault zone fabric and fault weakness; Nature 462 907-910, doi: 10.1038/nature08585.

Crosby A, White N, Edwards G and Shillington D J 2008 Evolution of the Newfoundland-Iberia conjugate rifted margins; Earth Planet. Sci. Lett. 273 214-226.

Daly E, Brown C, Stark C P and Ebinger C J 2004 Wavelet and multitaper coherence methods for assessing the elastic thickness of the Irish Atlantic margin; Geophys. J. Int. 159(2) 445-459.

Dean S M, Minshull T A, Whitmarsh R B and Louden K E 2000 Deep structure of the ocean-continent transition in the southern Iberia Abyssal Plain from seismic refraction profiles: The IAM-9 transect at $40^{\circ} 20^{\prime} \mathrm{N} ;$ J. Geophys. Res. 105 5859-5885.

Enachescu M E 1992 Enigmatic basins offshore Newfoundland; Canadian J. Explor. Geophys. 28(1) 44-61.

Forsyth D W 1985 Subsurface loading and estimates of the flexural rigidity of continental lithosphere; J. Geophys. Res. 90 12,623-12,632.
Funck T, Hopper J R, Larsen H C, Louden K E, Tucholke B E and Holbrook W S 2003 Crustal structure of the ocean-continent transition at Flemish Cap: Seismic refraction results; J. Geophys. Res. 108(B11) 2531, doi: 10.1029/2003JB001434.

Groupe Galice 1979 The continental margin off Galicia and Portugal: Acoustical Stratigraphy, dredge stratigraphy and structural evolution. In: Initial Reports Deep Sea Drilling Project 47B, Sibuet J C, Ryan W B F, et al, 633-662. U.S. Government Drilling Printing Office, Washington D.C.

Holdsworth R E 2004 Weak faults - rotten cores; Science 303 181-182.

Hopper J R, Funck T, Tucholke B E, Larsen H C, Steven Holbrook W, Louden K E, Shillington D and Lau H 2004 Continental breakup and the onset of ultraslow seafloor spreading off Flemish Cap on the Newfoundland rifted margin; Geology 32(1) 93-96, doi: 10.1130/G19694.1.

Jansa L F and Wade J A 1975 Geology of the continental margin off Nova Scotia and Newfoundland; In: Offshore geology of eastern Canada, Regional Geology 2 51-105.

Keen C E and de Voogd B 1988 The continent-ocean boundary at the rifted margin off eastern Canada: New results from deep seismic reflection studies; Tectonics 7 107-124.

Keen C E and Dehler S A 1997 Extensional styles and gravity anomalies at rifted continental margins: Some North Atlantic examples; Tectonics 16(5) 744-754.

Kirby J F and Swain C J 2008 An accuracy assessment of the fan wavelet coherence method for elastic thickness estimation; Geochem. Geophys. Geosyst. 9 Q0302227.

Kooi H, Cloetingh S and Burrus J 1992 Lithospheric necking and regional isostasy at extensional basins 1 . Subsidence and gravity modelling with an application to the Gulf of Lions Margin (SE France); J. Geophys. Res. 97(B12) $17,553-17,572$.

Kumar P, Yuan X, Kumar M R, Kind R, Li X and Chadha R K 2007 The rapid drift of the Indian tectonic plate; Nature 449 894-897.

Lau K W H, Keith E L, Deemer S, Hall J, John R H, Tucholke B E, Holbrook W S and Larsen H C 2006 Crustal structure across the Grand Banks Newfoundland Basin Continental Margin - II. Results from a seismic reflection profile; Geophys. J. Int. 167 157-170.

Madsen J A, Forsyth D W and Detrick R S 1984 A new isostatic model for the east Pacific Rise crest; J. Geophys. Res. 89 9997-10,016.

Mckenzie D 2003 Estimating Te in the presence of internal loads; J. Geophys. Res. 108, 2438, 21 pp., doi: 10.1029/2002JB001766.

Mckenzie D 2010 The influence of dynamically supported topography on estimates of Te; Earth Planet. Sci. Lett. 295 127-138.

Mckenzie D and Fairhead D 1997 Estimates of the effective elastic thickness of the continental lithosphere from Bouguer and free air gravity anomalies; J. Geophys. Res. 102 27,523-27,552.

Montadert L, Roberts D G, De Charpal O and Guennoc P 1979 Rifting and subsidence of the northern continental margin of the Bay of Biscay; In: Initial Reports Deep Sea Drilling Project, 80.

Moore D E and Rymer M 2007 Talc bearing serpentinites and the creeping section of the San Andreas fault; Nature 448 795-797, doi: 10.1038/nature06064.

National Oceanic and Atmospheric Administration 2003 General Bathymetric Chart of Oceans, http://www.ngdc. noaa.gov/mgg/gebco/grid/development.pdf

Parker R L 1972 The rapid calculation of potential anomalies; Geophys. J. R. Astron. Soc. 31 447-455.

Pegrum R M and Mounteney N 1978 Rift basins flanking North Atlantic Ocean and their relation to 
North Sea area; Amer. Assoc. Petrol. Geol. Bull. 62(3) 419-441.

Percival D B and Walden A T 1993 Spectral Analysis for Physical Applications: Multitaper and Conventional Univariate Techniques (New York: Cambridge Univ. Press).

Pollack H N, Hurter S J and Johnson J R 1993 Heat flow from the earth's interior: Analysis of the global data set; Rev. Geophys. 31(3) 267-280.

Rajesh R S and Mishra D C 2004 Lithospheric thickness and mechanical strength of the Indian shield; Earth Planet. Sci. Lett. 225 319-328.

Reid I D 1994 Crustal structure of a nonvolcanic rifted margin east of Newfoundland; J. Geophys. Res. 99 15,16115,180 .

Robert D G, Montadert L and Searle R C 1979b The western Rockall Plateau; Stratigraphy and structural evolution; In: Initial Reports Deep Sea Drilling Project 48 1061-1088.

Simons F J, Zuber M T and Korenaga J 2000 Isostatic response of the Australian lithosphere: Estimation of the effective elastic thickness and anisotropy using multitaper spectral analysis; J. Geophys. Res. 105 19,163-19,184.

Simons F J, Hilst R D V D and Zuber M T 2003 Spatiospectral localization of isostatic coherence anisotropy in Australia and its relation to seismic anisotropy: Implication for lithospheric deformation; J. Geophys. Res. 108(B5) ETG 1-8.

Sleep N H 1971 Thermal effects of the formation of Atlantic continental margins break-up; Geophys. J. R. Astron. Soc. 24 325-350.

Srivastava S P and Tapscott C R 1986 Plate kinematics of the North Atlantic; In: The Western North Atlantic Region, The Geology of North America; Soc. of Am., Boulder, Colo. 379-404.

Srivastava S P, Sibuet J-C, Cande S, Roest W R and Reid I R 2000 Magnetic evidence for slow seafloor spreading during the formation of the Newfoundland and Iberian margins; Earth Planet. Sci. Lett. 182 61-76.
Stephen J and Singh S B 2003 Elastic thickness and isostatic coherence anisotropy in the South Indian Peninsular Shield and its implications; Geophys. Res. Lett. 30(16), doi: 10.1029/2003GL017686.

Tassara A, Swain C, Hackney R and Kirby J 2007 Elastic thickness of South America estimated using wavelets and satellite derived gravity data; Earth Planet. Sci. Lett. 253 $17-26$.

Tiwari V M, Diament M and Singh S C 2003 Analysis of satellite gravity and bathymetry data over Ninety-East Ridge: Variation in the compensation mechanism and implication for emplacement process; J. Geophys. Res. 108 ETG13.1-ETG13.16.

Tucholke B E, Austin J A Jr and Uchupi E 1989 Crustal structure and riftdrift evolution of the Newfoundland Basin; In: Extensional tectonics and stratigraphy of the North Atlantic Margins (eds) Tankard A J and Balkwill $\mathrm{H}$ R, American Association of Petrology and Geology, Tulsa, 247-263.

Watts A B 1978 An analysis of isostasy in the world's oceans. 1: Hawaiian-Emperor Seamount Chain; J. Geophys. Res. 83 5989-6004.

Watts A B 2001 Isostasy and Flexure of the Lithosphere (Cambridge: Cambridge Univ. Press).

Watts A B and Stewart J 1998 Gravity anomaly and segmentation of the continental margin offshore West Africa; Earth Planet. Sci. Lett. 156 239-252.

Weissel J K and Karner G D 1989a Flexural uplift of rift flanks due to mechanical unloading of the lithosphere during extension; J. Geophys. Res. 94(B10) 13,91913,950 .

Zoback M L 1992 First- and second-order patterns of stress in the lithosphere: The World Stress Map Project; J. Geophys. Res. 97 11,703-11,728.

Zoback M D et al 1987 New evidence on the state of stress of the San Andreas fault system; Science 238 11051111 . 